Введение. Лечение пациентов с острым некротизирующим панкреатитом (ОНП) на фоне постоянно растущей заболеваемости и стабильно высокой летальности при тяжелых формах заболевания остается нерешенной задачей в ургентной абдоминальной хирургии.

Цель исследования - выявить возможности иммуногистохимических методов в исследовании ранних морфологических изменений забрюшинной клетчатки у пациентов с острым некротизирующим панкреатитом.

Материалы и методы. В статье представлены результаты иммуногистохимического исследования биоптатов забрюшинной клетчатки пациентов с острым некротизирующим панкреатитом, взятых в ранней фразе заболевания (первые 72 часа) с антителами к CD 34, ииклооксигеназе 2, фрракциям комплемента C1q и C3c, иммуноглобулинам A, G, M, интерлейкину 18, фрибриногену, трансформирующему фрактору роста бета 1 (TGF- $\beta$ 1), эндотелиальному фрактору роста сосудов (VEGF).

Результаты. Проведенные исследования показали, что при развитии острого панкреатита в забрюшинной клетчатке происходит активация циклооксигеназы 2, идет накопление экссудата, содержащего компоненты комплемента C1q и C3c, иммуноглобулины A, G и M, цитокин интерлейкин 18, фрибриноген, а также фракторы роста - TGF- $\beta 1$ u VEGF.

Заключение. Полученные результаты свидетельствуют о том, что при остром панкреатите иммуногистохимические методы могут быть успешно использованы для выявления иммунных и воспалительных биомаркеров.

Ключевые слова: острый некротизирующий панкреатит, цитокины, забрюшинная клетчатка, иммуногистохимия.

\title{
FIRST TIME EXPERIENCE OF APPLICATION OF IMMUNE HISTOCHEMICAL TESTS OF THE RETROPERITONEAL TISSUE IN THE EARLY PHASE OF ACUTE NECROTIZING PANCREATITIS ${ }^{1}$ V. N. Belorusets, ${ }^{1}$ A. S. Karpitski, ${ }^{2}$ T. A. Letkovskaya ${ }^{1}$ Brest Regional Hospital, Brest, Belarus ${ }^{2}$ Belarusian State Medical University, Minsk, Belarus
}

Background. Treatment of patients with acute necrotizing pancreatitis (SNP) against the background of an evergrowing incidence and stably high mortality in severe forms of the disease has remained an unresolved task in urgent abdominal surgery.

Objective - to identify the capabilities of immune histochemical tests in the study of early morphological changes in retroperitoneal tissue of patients with acute necrotizing pancreatitis.

Materials and methods. The article presents the results of immune histochemical studies of retroperitoneal tissue biopsy samples of patients with acute necrotizing pancreatitis, taken in the early phase of the disease (within first 72 hours), with antibodies to CD 34, Cyclooxygenase 2 (COX2), C1q Complement (C1q), C3c Complement (C3c), Immunoglobulin A (IgA), Immunoglobulin G (IgG), Immunoglobulin M (IgM), Interleukin 18 (IL 18), Fibrinogen, Transforming growth factor beta 1 (TGF- $\beta$ 1), Vascular Endothelial Growth Factor (VEGF).

Results. It has been proved that in case of acute pancreatitis development in retroperitoneal space tissues, one can observe the activation of cyclooxygenase 2, accumulation of exudate that contains the components of C1q and C3c complements, as well as $A, G$ and $M$ immunoglobulins, proinflammatory cytokine interleukin 18, fibrinogen, and also growth factors - TGF- $\beta 1$ and VEGF.

Conclusion. The obtained results indicate that in acute pancreatitis, immune histochemical methods can be successfully used to detect immune and inflammatory biomarkers.

Keywords: acute necrotizing pancreatitis, cytokines, retroperitoneal tissue, immune histochemical tests.

Автор, ответственный за переписку:

Белорусец Виктор Николаевич; Брестская областная больница; e-mail: victorbelorusets@yandex.ru
Corresponding author

Belorusets Victor (corresponding author); Brest regional hospital; e-mail: victorbelorusets@yandex.ru 


\section{Для цитирования:}

Белорусец, В. Н. Первый опыт применения иммуногистохимических методов исследования забрюшинной клетчатки в ранней фразе острого некротизирующего панкреатита / В. Н. Белорусец, А. С. Карпицкий Т. А. Летковская // Гепатология и гастроэнтерология. 2019. Т. 3, № 2. С. 197-205. https://dx.doi.org/ 10.25298/2616-5546-2019-3-2-197-205.

\section{For citation:}

Belorusets VN, Karpitski AS, Letkovskaya TA. First experience of application of immune histochemical tests of the retroperitoneal tissue in the early phase of acute necrotizing pancreatitis. Hepatology and Gastroenterology. 2019;3(2):197205. https://dx.doi.org/ 10.25298/2616-5546-2019-3-2-197-205.

\section{Введение}

Лечение пациентов с острым некротизирующим панкреатитом (ОНП) остается нерешенной задачей в ургентной абдоминальной хирургии. Постоянно растущая заболеваемость и стабильно высокая летальность при тяжелых формах заболевания не позволяет считать результаты удовлетворительными. Несмотря на широкое внедрение высокотехнологичных методов диагностики и лечения в клиническую практику, послеоперационная летальность не опускается ниже 11-25\% даже в специализированных стационарах [1].

В современном понимании патофизиология острого панкреатита (ОП) подразумевает сложный каскад патологических реакций, результатом которого становится некротическое поражение ткани поджелудочной железы (Пж) и забрюшинной клетчатки (ЗК), системный воспалительный ответ и органная недостаточность. По мнению большинства исследователей, активация ферментов - лишь первичное пусковое звено в развитии местных и системных воспалительных реакций. Активные ферменты и токсины инициируют местное воспаление, которое приводит к локальному продуцированию воспалительных медиаторов макрофагами, лимфоцитами и нейтрофрилами, мигрировавшими из сосудистого русла. Происходит высвобождение цитокинов. Дисбаланс между провоспалительными и регуляторными цитокинами - один из важнейших механизмов патогенеза воспаления. При ОП цитокины, вырабатывающиеся в ПЖ, попадают в экссудат и системный кровоток, индуцируют каскад цитокиновых реакций в других органах. Развивается системный воспалительный ответ. Наряду с деструкцией ПЖ возникают экстрапанкреатические нарушения, тяжесть которых во многом определяет прогноз заболевания.

Особенности анатомического расположения Пж способствуют вовлечению в патологический процесс больших массивов ЗК. Многие авторы считают перипанкреатический некроз не осложнением, а неотъемлемым компонентом ОНП [2, 3]. Степень вовлечения забрюшинных клетчаточных пространств в деструктивный процесс - важнейший прогностически неблагоприятный фрактор, и прямо коррелирует с летальностью [4]. Вместе с тем морфологические изменения в ЗК, предшествующие ее некротическому поражению в ранней фазе ОНП, изучены недоста- точно. Речь идет о первых 3-5 сутках от начала заболевания. Открытые оперативные вмешательства в эти сроки без крайней необходимости считаются тактической ошибкой и предпринимаются в редких случаях. Количество секционного материала не позволяет провести исследования ранних морфологических изменений в связи с тем, что большинство летальных исходов происходит значительно позднее. Корректные модели воспроизведения парапанкреатита в экспериментальных исследованиях отсутствуют ввиду интраперитонеального расположения поджелудочной железы у лабораторных животных. Большинство хирургов, использующих в раннем лечебном комплексе лапароскопические операции, ограничиваются дренированием брюшной полости без вмешательства на ЗК.

Активное внедрение в лечебную практику метода лапароскопического дренирования забрюшинной клетчатки в ранней фазе острого некротизирующего панкреатита (патент РБ на изобретение № 21055 от 09.02.2017; Инструкция по применению № 062 - 0618) позволило нам получить материал в виде микробиоптатов для изучения морфологических изменений, происходящих в ЗК пациентов с ОНП с первых суток от начала заболевания. Исследование одобрено комитетом по этике Брестской областной больницы (протокол № 1 от 09.01.2015г.), комитетом по биомедицинской этике учреждения образования «Гродненский государственный медицинский университет» (протокол № 2 от 06.01.2015 г.). От всех пациентов получено информированное согласие на участие в проводимом исследовании. Взятие биоптатов производилось в зоне максимальных визуальных изменений. Чаще всего это геморрагическое пропитывание ЗК экссудатом в области боковых каналов живота. Биоптаты фриксировали в течение 24 часов в $10 \%$ растворе формалина. Для изготовления гистологических препаратов использовали парафиновый метод заливки.

Цель исследования - определить возможности иммуногистохимических методов в исследовании ранних морфологических изменений забрюшинной клетчатки у пациентов с острым некротизирующим панкреатитом.

\section{Материалы и методы}

Иммуногистохимические (ИГХ) исследования выполнены на базе кафедры патологической 
анатомии учреждения образования «Белорусский государственный медицинский университет». Из имеющихся в нашем распоряжении образцов биопсийного материала 22 пациентов с ОНП для проведения ИГХ исследования были отобраны четыре с наибольшим количеством материала в парафиновых блоках, достаточным для изготовления необходимого количества серийных срезов. Учитывались также сроки получения биопсийного материала от начала заболевания. В таблице 2 время операции в часах указано в первой графе в скобках. Срезы толщиной 5 мкм окрашивались гематоксилином и эозином (H\&E), реактивом Шиффра (PAS) и по MSB (Martius Scarlet Blue). Реактив Шиффра применен как наиболее распространенный метод выявления полисахаридов гликопротеидов, протеогликанов. Метод окраски MSB предложен в 1962 г. А. C. Lendrum для определения времени коагуляции фибрина. ИГХ исследование выполнено с антителами к CD 34, Cyclooxygenase 2 (COX2), C1q Complement (C1q), C3c Complement (C3c), Immunoglobulin A (IgA), Immunoglobulin G (IgG), Immunoglobulin M (IgM), Interleukin 18 (IL 18), Fibrinogen, Transforming growth factor beta 1 (TGF- $\beta$ 1), Vascular Endothelial Growth Factor (VEGF).

При проведении ИГХ окрашивания в качестве позитивного контроля для каждого из маркеров использовали ткани и органы, рекомендованные производителями антител, в качестве негативного контроля - исключение первичного антитела. Для выявления иммуноглобулинов классов A, M, G, фрракций комплемента C3 и C1q, а также для CD 34, VEGF использовались коммерческие антитела фрирмы DAKO Cytomation (Denmark). Для выявления COX2, IL 18, Fibrinogen, TGF- $\beta 1$ использовались коммерческие антитела фрирмы Abcam (England). ИГХ исследование проводи- ли после отработки протоколов, в которых для каждого первичного антитела было установлено оптимальное $\mathrm{pH}$, время экспозиции в демаскировочном буфере, оптимальное разведение и время экспозиции с хромогеном диаминобензидином (DAB). Данные о первичных антителах, демаскировочных буферах, системах визуализации и времени экспозиции хромогена представлены в таблице 1.

Иллюстрации микропрепаратов выполнялись с использованием цифровой фотокамеры DC200 производства фрирмы Leica.

\section{Результаты и обсуждение}

Интерпретация результатов ИГХ исследования молекулярных биомаркеров осуществлялась исходя из локализации и интенсивности окрашивания ткани хромогеном DAB. Критерии балльной оценки интенсивности окрашивания: 0 баллов - негативное окрашивание «-», 1 балл слабая интенсивность (+), 2 балла - умеренная интенсивность (++), 3 балла - сильная интенсивность $(+++)$.

Результаты иммуногистохимического исследования молекулярных биомаркеров представлены в таблице 2 .

При окраске препаратов гематоксилином и эозином (H\&E) характерной особенностью поражения ЗК при ОП стало наличие очаговых отложений бесструктурных эозинофильных масс, встречавшихся во всех без исключения препара$\operatorname{Tax}[5]$.

На сегодняшний день нет доказательств того, что какой-либо конкретный фактор вызывает острый панкреатит. Однако исследования последних лет показали, что уровень таких цитокинов, как эндотелиальный фактор роста сосудов (VEGF) и трансформирующий фактор роста бета (TGF- $\beta$ ) у пациентов с ОП достоверно выше, чем

Таблица 1. - Характеристика антител и особенности обработки материала

Table 1. - Antibodies characteristics and material processing peculiarities

\begin{tabular}{|c|c|c|c|c|c|}
\hline $\begin{array}{c}\text { Первичное } \\
\text { антитело }\end{array}$ & Происхождение антител & $\begin{array}{c}\text { Демаски } \\
\text { ровочный буфер, pH }\end{array}$ & $\begin{array}{c}\text { Визуализирующая } \\
\text { система }\end{array}$ & Разведение & $\begin{array}{c}\text { Время экспозиции } \\
\text { хромогена DAB }\end{array}$ \\
\hline CD 34 & mouse monoclonal & $\mathrm{pH}=6.0$ & EnVision & $1: 200$ & 5 мин. \\
\hline $\operatorname{cox} 2$ & rabbit polyclonal & $\mathrm{pH}=9.0$ & EnVision & $1: 50$ & 3 мин. \\
\hline С1qя & rabbit polyclonal & $\mathrm{pH}=9.0$ & EnVision & $1: 10000$ & 3 мин. \\
\hline $\mathrm{C} 3 \mathrm{c}$ & rabbit polyclonal & $\mathrm{pH}=6.0$ & EnVision & $1: 10000$ & 3 мин. \\
\hline $\lg A$ & rabbit polyclonal & $\mathrm{pH}=9.0$ & EnVision & $1: 50000$ & 3 мин. \\
\hline $\lg G$ & rabbit monoclonal & $\mathrm{pH}=9.0$ & EnVision & $1: 50000$ & 3 мин. \\
\hline $\lg M$ & rabbit polyclonal & $\mathrm{pH}=6.0$ & EnVision & $1: 50000$ & 3 мин. \\
\hline IL 18 & rabbit monoclonal & $\mathrm{pH}=9.0$ & EnVision & $1: 100$ & 5 мин. \\
\hline Fibrinogen & rabbit polyclonal & $\mathrm{pH}=9.0$ & EnVision & $1: 100$ & 5 мин. \\
\hline TGF- $\beta 1$ & rabbit monoclonal & $\mathrm{pH}=9.0$ & EnVision & $1: 1000$ & 5 мин. \\
\hline VEGF & mouse monoclonal & $\mathrm{pH}=9.0$ & EnVision & $1: 200$ & 5 мин. \\
\hline
\end{tabular}


Таблица 2. - Характер экспрессии молекулярных биомаркеров

Table 2. - The expression pattern of molecular biomarkers

\begin{tabular}{|c|c|c|c|c|c|c|c|c|c|c|c|}
\hline $\begin{array}{c}\text { Случаи } \\
\text { (время операции) }\end{array}$ & $\begin{array}{l}\text { ले } \\
\text { वे }\end{array}$ & $\begin{array}{l}\tilde{x} \\
0 \\
0\end{array}$ & $\frac{\sigma}{U}$ & ల్ల & వ్ర & OD & 面 & $\stackrel{\infty}{=}$ & 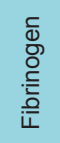 & 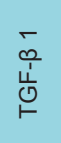 & 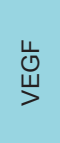 \\
\hline $1(334)$ & +++ & + & + & + & + & ++ & + & - & + & +++ & +++ \\
\hline $2(484)$ & +++ & ++ & ++ & ++ & ++ & + & ++ & ++ & + & + & ++ \\
\hline $3(554)$ & +++ & ++ & ++ & ++ & ++ & + & ++ & - & +++ & ++ & ++ \\
\hline $4(724)$ & +++ & +++ & ++ & ++ & +++ & +++ & +++ & - & +++ & +++ & +++ \\
\hline $\begin{array}{l}\text { тенденция } \\
\text { динамики } \\
\text { экспрессии } \\
\text { маркеров }\end{array}$ & - & $\uparrow$ & $\uparrow /-$ & $\uparrow /-$ & $\uparrow$ & $\downarrow \uparrow$ & $\uparrow$ & - & $\uparrow$ & $\downarrow \uparrow$ & $\downarrow \uparrow$ \\
\hline
\end{tabular}

у здоровых людей и у пациентов с абдоминальной болью непанкреатогенного характера. [6, 7, $8,9]$. При экспериментальном панкреатите, индуцированном ишемией/реперфузией, максимальное содержание VEGF в ацинарных клетках ПЖ отмечалось от 1 до 24 ч, TGF-ß от 5 до 24 ч [10].

VEGF секретируется различными нормальными и трансорормированными клетками и является гомодимерным гликопротеином с молекулярной массой приблизительно 45 кДа. VEGF, как наиболее мощный ангиогенный фактор, увеличивает проницаемость сосудов, стимулирует митогенез и миграцию эндотелиальных клеток [6]. Активация эндотелиальных клеток способствует миграции нейтрофилов, моноцитов и лимфоцитов из сосудистого русла в ПЖ, а медиаторы, высвобождаемые данными клетками, такие как нейтрофрильная эластаза, могут быть гораздо более разрушительными, чем ферменты ПЖ [11].

TGF- $\beta 1$ - полипептидный член суперсемейства трансформирующих фракторов роста бета-цитокинов. Это секретируемый белок, который выполняет многие клеточные функции, включая контроль роста, пролиферации, дифференцировки, подвижности клеток и апоптоз, играет важную роль в контроле иммунной системы и проявляет активность в отношении разных типов клеток. Большинство иммунных клеток секретируют TGF- $\beta$ 1, а сывороточные протеиназы повышают высвобождение TGF- $\beta 1$ из неактивного состояния. TGF- $\beta$ - доминирующий медиатор, регулирующий фиброгенез [12, 13].

Результат ИГХ реакции с антителами к TGF- $\beta$ 1 был представлен в виде окрашивания в коричневый цвет содержимого и эндотелия отдельных сосудов, цитоплазмы клеток воспалительного инфильтрата, а также очаговых скоплений экссудата в жировой клетчатке (рис. 1). Экспрессия TGF-ß 1 обнаружена во всех исследованных случаях. Как видно из таблицы 2, степень интенсивности ИГХ реакции варьировала от слабой до выраженной, без отчетливой зависимости от временного фрактора.
Результат ИГХ реакции с антителами к VEGF представлен в виде окрашивания в коричневый цвет содержимого и эндотелия отдельных сосудов, цитоплазмы клеток воспалительного инфильтрата, а также очаговых скоплений экссудата в жировой клетчатке (рис. 2). Экспрессия VEGF обнаружена во всех исследованных случаях. Как видно из таблицы 2, степень интенсивности ИГХ реакции варьировала от средней до выраженной. Зависимость от временного фактора также отчетливо не прослеживалась.

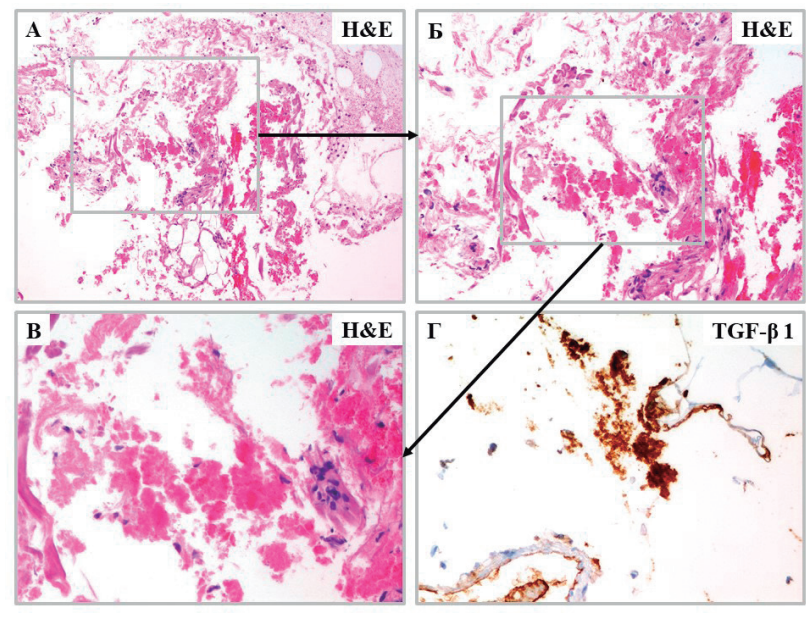

Рисунок 1. - Случай № 1. А - ткань забрюшинного пространства со скоплениями хлопьевидного эозинофильного экссудата (окраска H\&E); 5 - то же, что на рисунке $A$, на большем увеличении (окраска H\&E); В - то же, что на рисунке Б, на большем увеличении (окраска H\&E); Г - выраженная (+++) экспрессия TGF- $\beta 1$ в очаговых скоплениях экссудата в жировой клетчатке, позитивное окрашивание клеток воспалительного инфильтрата и эндотелия сосудов (ИГХ окрашивание с антителами к TGF- $\beta$ 1, хромоген DAB, контрокрашивание гематоксилином Майера); $A-\times 100$, Б - ×200; B - ×400, Г- ×400

Figure 1. - Case № 1. A - retroperitoneal tissue with clusters of flaky eosinophilic exudate (H\&E stain); $\overline{-}$ - the same as in Figure $A$, at higher magnification (staining H\&E); $B$ - the same as in Figure 5 , at higher magnification (H\&E stain); $\Gamma$ - apparent (+++) expression of TGF- $\beta 1$ in focal accumulations of exudate in fatty tissue, positive staining of cells of inflammatory infiltrate and vascular endothelium (IHC staining with antibodies to TGF- $\beta$ 1, DAB chromogen, Mayer hematoxylin counter-staining); $A-\times 100,5-\times 200 ; B-\times 400$, $\Gamma-\times 400$ 

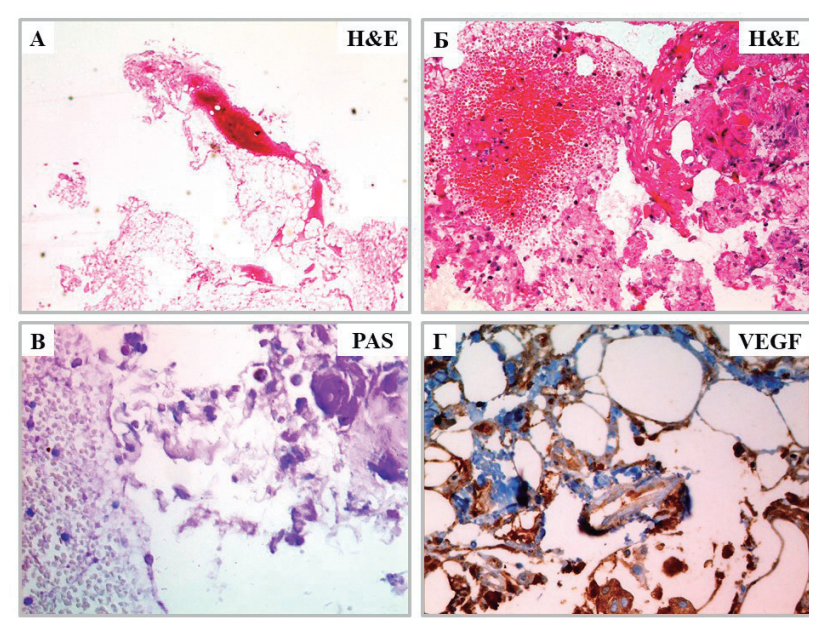

Рисунок 2. - Случай № 3. А - ткань забрюшинного пространства с кровоизлияниями и наличием эозинофильного экссудата (окраска H\&E); 5 - ткань забрюшинного пространства с кровоизлияниями и наличием эозинофильного экссудата (окраска H\&E); В - ткань забрюшинного пространства с кровоизлияниями и наличием ШИК-позитивных скоплений (окраска PAS); Г - выраженная (+++) экспрессия VEGF 1 в очаговых скоплениях экссудата в жировой клетчатке, позитивное окрашивание клеток воспалительного инфильтрата и эндотелия сосудов (ИГХ окрашивание с антителами к VEGF, хромоген DAB, контрокрашивание гематоксилином Майера); - ×100, Б - ×200; В - ×400, Г- ×400 Figure 2. - Case № 3. A - retroperitoneal tissue with hemorrhages and the presence of eosinophilic exudate (H\&E stain); 5 - retroperitoneal tissue with hemorrhages and the presence of eosinophilic exudate (H\&E stain); $B$ - retroperitoneal tissue with hemorrhages and the presence of CHIC-positive clusters (PAS stain); $\Gamma$ - apparent (+++) expression of VEGF 1 in focal accumulations of exudate in fatty tissue, positive staining of cells of inflammatory infiltrate and vascular endothelium (IHC staining with antibodies to VEGF, DAB chromogen, Mayer hematoxylin counter-staining); $A-\times 100,5-\times 200 ; B-\times 400, \Gamma-\times 400$

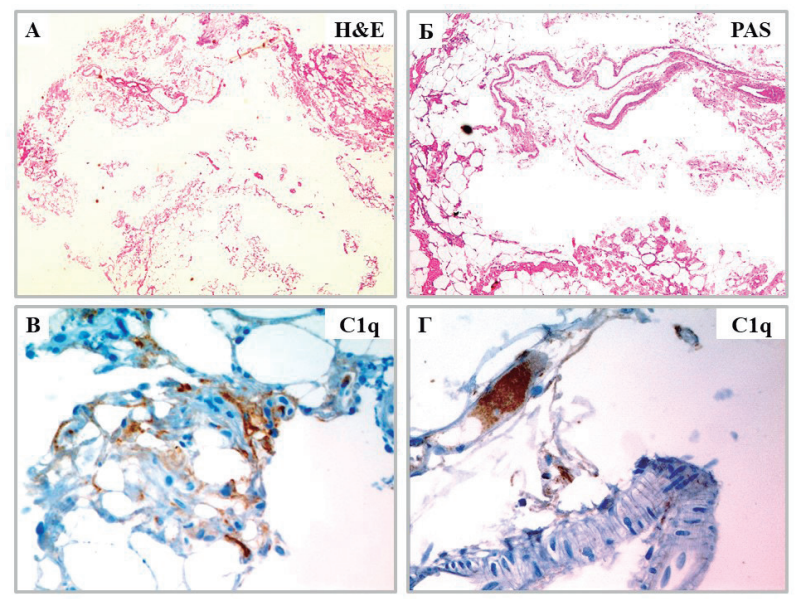

Рисунок 3. - Случай № 3. А, Б - ткань забрюшинного пространства (окраска H\&E); B, Г- -умеренная (++) экспрессия компонента комплемента C1q в просвете сосудов и в виде депозитов в эндотелии (ИГХ окрашивание с антителами к C1q хромоген DAB, контрокрашивание гематоксилином Майера); - ×50, Б - ×100; B - ×200, Г - ×400 Figure 3. - Case № 3. A, 5 - retroperitoneal tissue (H\&E stain); $B, \Gamma$-moderate (++) expression of the component of complement C1q in the lumen of blood vessels and in the form of deposits in the endothelium (IHC staining with antibodies to C19 DAB chromogen, Mayer hematoxylin counter-staining); $A-\times 50,5-\times 100 ; B-\times 200, \Gamma-\times 400$

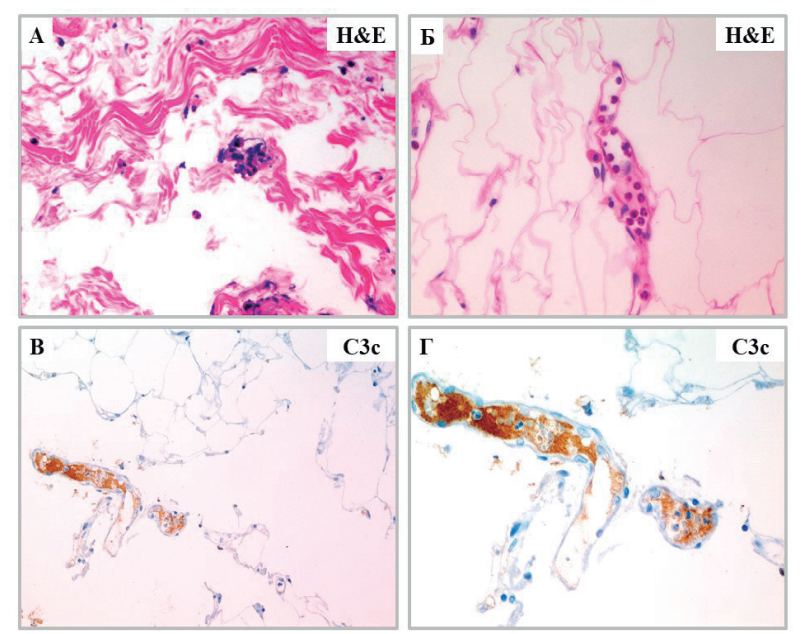

Рисунок 4. - Случай № 4. А - ткань забрюшинного пространства с очаговой полиморфно-клеточной инфрильтрацией (окраска H\&E); Б - лейкостаз в сосуде с лейкодиапедезом (окраска H\&E); В, Г- умеренная (++) экспрессия С 3 с в виде окрашивания содержимого сосудов (ИГХ окрашивание с антителами к C3c, хромоген DAB, контрокрашивание гематоксилином Майера); $A-\times 200,5-\times 400 ; B-\times 100, \Gamma-\times 400$ Figure 4. - Case № 4. A - retroperitoneal tissue with focal polymorphic cell infiltration (H\&E stain); 5 - leukostasis in a vessel with leukodiapadesis (H\&E stain); $B, \Gamma-$ moderate (++) expression of $C 3 c$, in the form of staining of blood vessels content (IHC staining with antibodies to C3C DAB chromogen, Mayer hematoxylin counter-staining); A - ×200, Б - ×400; $B-\times 100, \Gamma-\times 400$

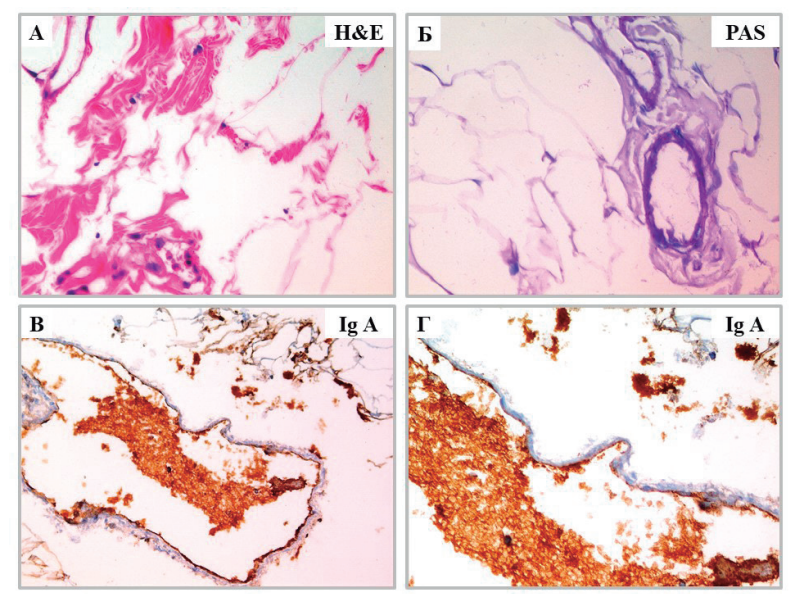

Рисунок 5. - Случай № 4. А - ткань забрюшинного пространства с лейкостазами (окраска H\&E); 5 - плазматическое пропитывание стенок мелких сосудов (окраска PAS); В, Г- выраженная (+++) экспрессия IgA в виде окрашивания содержимого сосудов, читоплазмы плазматических клеток и очаговых скоплений экссудата в жировой клетчатке (ИГХ окрашивание с антителами к IgA, хромоген DAB, контрокрашивание гематоксилином Майера) Figure 5. - Case № 4. A - retroperitoneal tissue with leukostasis (H\&E stain); 5 - plasma impregnation of small vessels walls (PAS stain); $B, \Gamma$ - apparent (+++) expression of IgA in the form of staining of blood vessels content, cytoplasm of plasma cells and focal accumulations of exudate in fatty tissue (IHC staining with antibodies to IgA, DAB chromogen, Mayer hematoxylin counter-staining)

Наряду с цитокинами значительный вклад в развитие системного воспалительного ответа вносит система комплемента. Система комплемента - основной механизм гуморального звена врожденного иммунитета. Как первая ли- 
ния защиты от патогенов, она инициирует ранний воспалительный ответ и связывает разные звенья гуморального и клеточного иммунитета. Еще в 1990 г. шведскими исследователями убедительно доказано повышение компонентов C3a и C5b-9 системы комплемента в сыворотке крови пациентов с ОП, показана также высокая корреляция с тяжестью заболевания по шкале Рансона. Авторы убедительно доказали, что перитонеальный экссудат у пациентов с ОП содержит высокие уровни С5а и мембраноатакующего комплекса комплемента [11].

Классический путь активации системы комплемента предполагает изначальную активацию C1 компонента иммуноглобулинами (lgM/lgG), что приводит к расщеплению С4 и С2. Продукты расщепления C4b и C2a образуют C3-конвертазу C4b2a классического пути, которая в свою очередь расщепляет центральный компонент C3 комплемента в анафилатоксин СЗа и опсонин $\mathrm{C} 3 \mathrm{~b}$.

При ОП активация комплемента, по-видимому, происходит не только классическим путем. Трипсин способен расщеплять и активировать центральные компоненты комплемента, что ведет к образованию анафилотоксинов С3а и С5a, которые в свою очередь могут вызывать все классические признаки воспаления. Генерируемые продукты активации комплемента являются мощными факторами локального и системного воспаления и вносят значительный вклад в развитие ССВО [15].

Результат ИГХ выявления компонентов комплемента C1q и C3c был однотипным: имело место окрашивание содержимого кровеносных сосудов, определялись мелкие депозиты в эндотелии некоторых мелких сосудов (рис. 3-4). Указанные изменения разной степени выраженности обнаружены во всех исследованных случаях. В биоптатах ЗК, взятых до 48 ч от начала заболевания экспрессия С1q и С3c была слабоинтенсивной (+) - 1 балл. В более поздних образцах (48 ч - 72 ч) - умеренная интенсивность $(++)$ - 2 балла (табл. 2).

Результат ИГХ выявления IgA, IgG и IgM был представлен в виде окрашивания в коричневый цвет содержимого сосудов, цитоплазмы плазматических клеток, а также в виде окрашивания очаговых скоплений экссудата в жировой клетчатке (рис. 5-7). Степень интенсивности ИГХ реакции варьировала от слабой до выраженной. Как видно из таблицы 2, для IgA и IgM отчетливо прослеживается нарастание интенсивности окрашивания в зависимости от сроков взятия материала. В образцах, полученных через 33 ч от начала заболевания, отмечалась слабая интенсивность (+) - 1 балл. В материале пациентов, оперированных через 48 и 55 ч от начала заболевания, интенсивность была 2 балла - умеренная (++). В

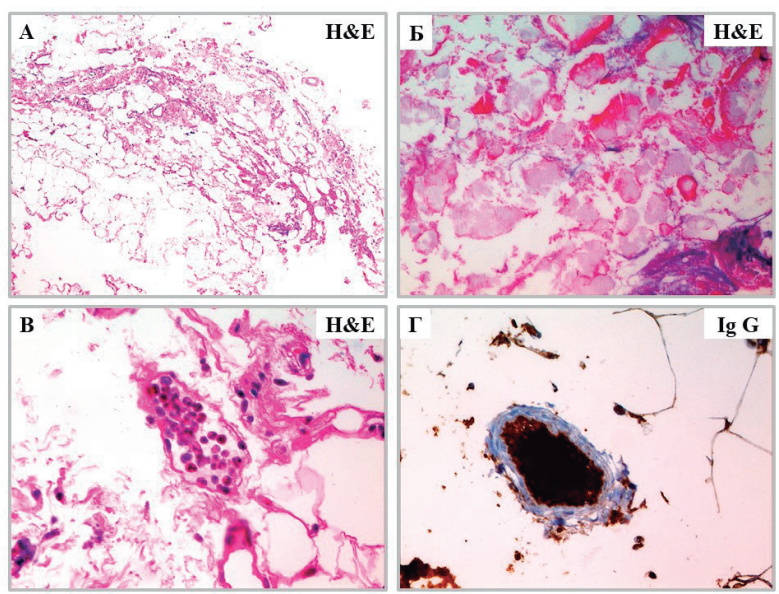

Рисунок 6.- Случай № 4. А - ткань забрюшинного пространства (окраска H\&E); Б - жировые некрозы в забрюшинной клетчатке (окраска H\&E); В - лейкостаз и лейкодиапедез (окраска H\&E); Г - выраженная (+++) экспрессия IgG в виде окрашивания содержимого сосудов, цитоплазмы плазматических клеток и очаговых скоплений экссудата в жировой клетчатке (ИГХ окрашивание с антителами к IgG, хромоген DAB, контрокрашивание гематоксилином Майера); $A-\times 50,5-\times 200 ; B-\times 400, \Gamma-\times 400$ Figure 6. - Case № 4. A - retroperitoneal tissue (H\&E stain); E - retroperitoneal fat necrosis (H\&E stain); B - leukostasis and leukodiapadesis (H\&E stain); $\Gamma$ - apparent (+++) expression of IgG in the form of staining of blood vessels content, cytoplasm of plasma cells and focal accumulations of exudate in fatty tissue (IHC staining with antibodies to IgG, DAB chromogen, Mayer hematoxylin counter-staining); $A-\times 50$, E- ×200; B- ×400, $\Gamma-\times 400$

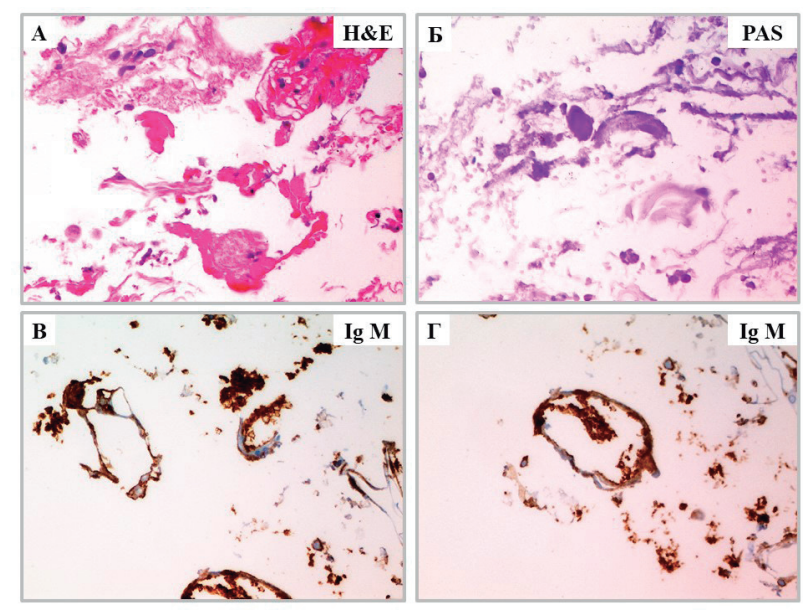

Рисунок 7. - Случай № 4. А - очаговые скопления эозинофильного экссудата в забрюшинном пространстве (окраска H\&E); Б - ШИК-позитивные очаговые скопления эозинофильного экссудата в забрюшинном пространстве (окраска PAS); В, Г- выраженная (+++) экспрессия IgM в виде окрашивания содержимого сосудов, цитоплазмы плазматических клеток и очаговых скоплений экссудата в жировой клетчатке (ИГХ окрашивание c антителами к IgM, хромоген DAB, контр-окрашивание гематоксилином Майера): $A$ - х400, Б - х400; B - х400, Г - ×400 Figure 7. - Case № 4. A - focal accumulations of eosinophilic exudate in the retroperitoneal space (H\&E stain); 5 - CHIC-positive focal accumulations of eosinophilic exudate in the retroperitoneal space (PAS stain); $B, \Gamma-$ apparent (+++) expression of IgM in the form of staining of blood vessels content, cytoplasm of plasma cells and focal accumulations of exudate in fatty tissue (IHC staining with antibodies to $\operatorname{lgM}, D A B$ chromogen, Mayer hematoxylin counter-staining). $A-\times 400,5-\times 400$; $B-\times 400, \Gamma-\times 400$ 

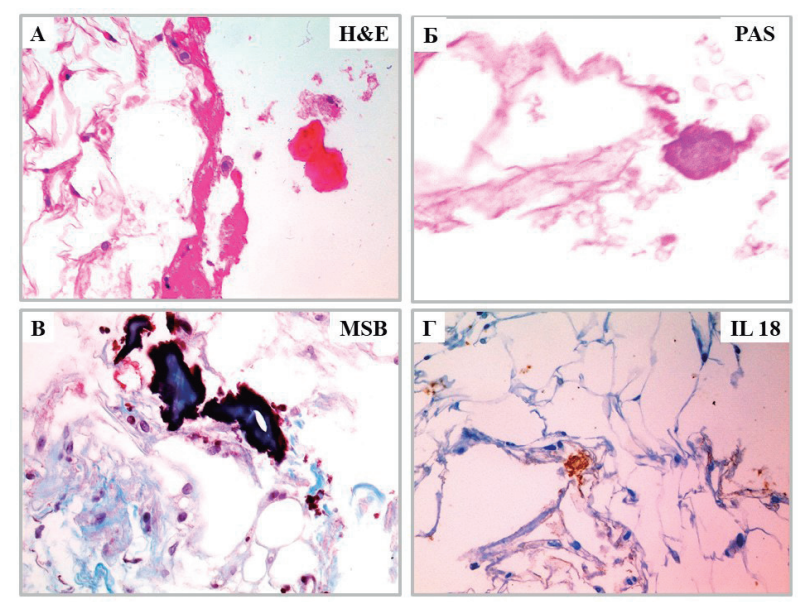

Рисунок 8. - Случай № 2. А - очаговые скопления эози нофильного экссудата в забрюшинном пространстве (окраска H\&E); Б - ШИК-позитивные очаговые скопления эозинофильного экссудата в забрюшинном пространстве (окраска PAS); В - сине-сриолетовое позитивное окраши вание на «старый» (>24 ч) фибрин скоплений экссудата в забрюшинном пространстве (окраска MSB); Г - умеренная (+) экспрессия IL 18 в виде окрашивания скоплений экссудата в жировой клетчатке (ИГХ окрашивание с антите лами к IL 18, хромоген DAB, контр-окрашивание гематоксилином Майера); $A-\times 400,5-\times 400 ; B-\times 400, \Gamma-\times 400$ Figure 8. - Case № 2. A - focal accumulations of eosinophilic exudate in the retroperitoneal space (H\&E stain); 5 - CHIC-positive focal accumulations of eosinophilic exudate in the retroperitoneal space (PAS stain); B - blue-violet positive staining for "old" (>24 hours) fibrin of exudate accumulations in the retroperitoneal space (MSB stain); $\Gamma$ - moderate (+) expression of IL 18 in the form of staining of clusters of exudate in fatty tissue (IHC staining with antibodies to IL 18, DAB chromogen, Mayer hematoxylin counter-staining); $A-\times 400,5-\times 400 ; B-\times 400, \Gamma-\times 400$
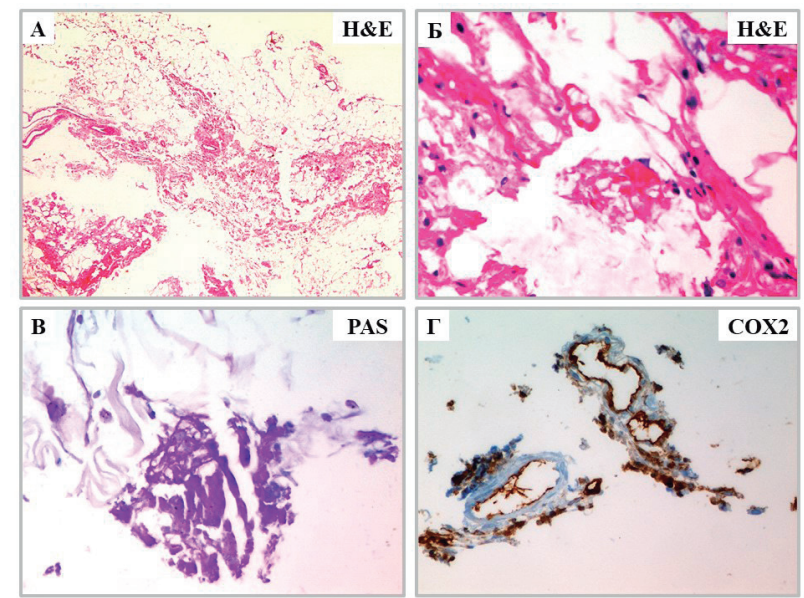

Рисунок 9. - Случай № 4. А - ткань забрюшинного пространства (окраска H\&E); Б - эозинофильный экссудат (окраска Н\&E); В - ШИК-позитивный экссудат (окраска PAS); Г - выраженная (+++) экспрессия COX2 в эндотелии сосудов, цитоплазме фибробластов и макрофрагов (ИГХ окрашивание с антителами к COX2, хромоген DAB, контр-окрашивание гематоксилином Майера); $A$ - ×50, Б - ×200; B - ×400, Г- ×200

Figure 9. - Case № 4. A - retroperitoneal tissue (H\&E stain); 5 eosinophilic exudate (H\&E stain); B - CHIC-positive exudate (PAS stain); $\Gamma$ - apparent (+++) expression of COX2 in vascular endothelium, cytoplasm of fibroblasts and macrophages (IHC staining with antibodies to COX2, DAB chromogen, Mayer hematoxylin counter-staining); $A-\times 50,5-\times 200 ; B-\times 400, \Gamma-\times 200$

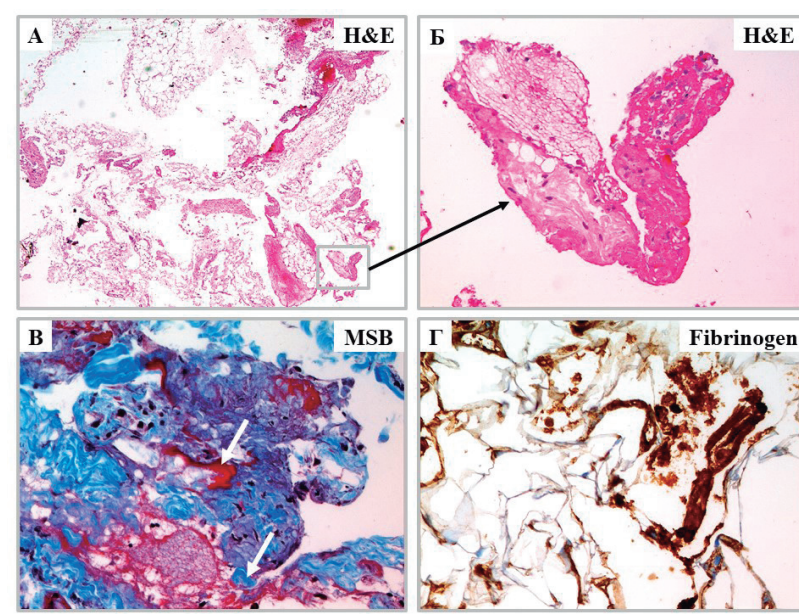

Рисунок 10. - Случай № 3. А - ткань забрюшинного пространства со скоплениями фрибринозного экссудата (окраска H\&E); Б - то же, что на рисунке $A$, на большем увеличении (окраска Н\&E); В - выстилка «молодым» (<12 4) фрибрином стенок сосудов (верхняя белая стрелка), наличие «старого» (>24 ч) фибрина в экссудате (окраска MSB); Г - выраженная (+++) экспрессия Fibrinogen в очаговых скоплениях экссудата в жировой клетчатке, в просвете сосудов (ИГХ окрашивание с антителами к Fibrinogen, хромоген DAB, контрокрашивание гематоксилином Майера); $A-\times 100,5-\times 400 ; B-\times 200, \Gamma-\times 400$ Figure 10. - Case № 3. A - retroperitoneal tissue with accumulations of fibrinous exudate (H\&E stain); $\overline{-}$ - the same as in Figure $A$, at higher magnification (H\&E coloring); $B$ - lining with "young" ( $<12$ hours) fibrin of the vessel walls (upper white arrow), the presence of "old" (> 24 hours) fibrin in exudate (MSB stain); $\Gamma$ - apparent (+++) expression of Fibrinogen in focal accumulations of exudate in adipose tissue, in the lumen of blood vessels (IHC staining with antibodies to Fibrinogen, DAB chromogen, Mayer hematoxylin counter-staining) $A-\times 100,5-\times 400 ; B-\times 200, \Gamma-$ $\times 400$

наиболее поздних образцах (72 ч) преобладала выраженная интенсивность окрашивания с антителами к $\lg \mathrm{A}, \lg \mathrm{G}$ и $\lg \mathrm{M}$.

Развитие системной воспалительной реакции при ОП - закономерная, но не фатальная реакция организма на повреждение, которой противодействует система противовоспалительных медиаторов (ИЛ-2, 4, 10, 11, 18, растворимые рецепторы к ФНО и антагонисты рецепторов ИЛ-1b, активация нейтрализации ФНО в печени) - синдром компенсаторного противовоспалительного ответа (CARS - compensatory antiinflammatory response syndrome)[16]. По данным Ueda T. с соавт., уровни сывороточного IL-18 у пациентов с острым панкреатитом (656+/-11 пг/ мл) были значительно выше, чем у здоровых добровольцев (126+/-пг/мл). Уровни IL-18 в сыворотке достоверно положительно коррелировали с оценкой тяжести по шкале Рансона [17]. Повышение уровня IL-18 в сыворотке может быть причиной острого панкреатит-ассоциированного повреждения печени.

Результат ИГХ выявления интерлейкина 18 (IL 18) был представлен в виде окрашивания в коричневый цвет отдельных очаговых скоплений экссудата в жировой клетчатке (рис. 8). Экспрессия IL 18 была обнаружена в материале 1 паци- 
ента. Степень интенсивности ИГХ реакции была умеренной (табл. 2).

Антиген CD34 является белком клеточной поверхности, регулятором адгезии[18]. Результат ИГХ выявления антигена CD 34 был представлен в виде очень четко окрашенных в коричневый цвет цитоплазмы и ядер эндотелиальных клеток сосудов, что позволило в дальнейшем при сравнении со стеклами, окрашенными другими антителами, четко видеть экспрессию вне просвета кровеносных сосудов.

Результат ИГХ выявления циклооксигеназы 2 (COX2) был представлен в виде очень четко окрашенных в коричневый цвет эндотелиальных клеток сосудов, а также цитоплазмы фибробластов и единичных макрофагов, определяемых в жировой клетчатке (рис. 9). Как видно из таблицы 2, экспрессия COX2 разной степени интенсивности выявлена во всех 4 исследованных случаях с постепенным нарастанием (в зависимости от сроков заболевания) - от 1 балла (33 ч) до 3 баллов (72 ч). Как известно, СОХ2 является индуцируемой, ее обнаружение в неповрежденных тканях является спорным. COX2 считается провоспалительным фрерментом, экспрессия которого стимулируется провоспалительными цитокинами на ранних стадиях воспаления [19]. Следовательно, экспрессия СОХ2 указывает на то, что реализованы пусковые процессы местной воспалительной реакции.

Результат ИГХ реакции с антителами к Fibrinogen, белку острой фразы воспаления был представлен в виде окрашивания в коричневый цвет содержимого отдельных сосудов, тромбов, а также очаговых скоплений экссудата в жировой клетчатке (рис. 10). Экспрессия Fibrinogen обнаружена во всех исследованных случаях. Как видно из таблицы 2, степень интенсивности ИГХ реакции варьировала от слабой в образцах, полученных через 33 и 48 ч, до выраженной - в более поздних биоптатах (55 и 72 ч).

\section{Выводы}

Таким образом, проведенное исследование показало, что использование иммуногистохимических методов - перспективное направление в изучении молекулярных механизмов патологических процессов при остром панкреатите.

\section{References}

1. Tolstoj AD, Panov VP, Krasnorogov VB, Vashetko RV, Skorodumov AV. Parapankreatit. Jetiologija, patogenez, diagnostika, lechenie. St. Petersburg: Jasnyj svet; 2003. 256 p. (Russian).

2. Shoroh GP, Shoroh SG. Ostryj destruktivnyj pankreatit [Acute destructive pancreatitis]. Minsk: Paradoks; 2013. 208 p. (Russian).

3. Lyzikov AN, Mayorov VM, Dundarov ZA, Avizhets YuN. Morfologicheskie osobennosti jekstrapankreaticheskogo porazhenija vnutrennih organov pri ostrom fermentativnom parapankreatite [Morphological features of extrapancreatic lesion of internal organs in acute enzymatic parapancreatitis] Problemy zdorovja $i$ jekologii [Problems of health and ecology]. 2014;40(2):61-66. (Russian).

4. Darvin VV, Onishchenko SV, Ilkanich Ala, Amiragian DS, Shirinskiĩ VG. Miniinvazivnye tehnologii v lechenii ostrogo pankreatita [Mini-invasive technologies for the acute pancreatitis treatment]. Hirurgija. Zhurnal imeni NI Pirogova [Journal Surgery named after NI Pirogov]. 2009;1:29-32. (Russian).

5. Belorusets VN, Karpitskij AS, Golubeva NN. Morfologicheskie izmenenija $v$ zabrjushinnoj kletchatke $\checkmark$ rannej faze ostrogo nekrotizirujushhego pankreatita [Morphological changes in the retroperitoneal fat tissue in the early phase of acute necrotizing pancreatitis]. Novosti hirurgii [Surgery News]. 2018;26(1):34-41. (Russian).

6. Nandy D, Mukhopadhyay D. Growth factor mediated signaling in pancreatic pathogenesis. Cancers. 2011;3(1):841-871. doi: 10.3390/cancers3010841.

7. Zagorodskikh EB, Cherkasov VA, Schekotova AP. Markery endotelialnoj disfunkcii $\mathrm{i}$ ih prognosticheskoe znachenie pri ostrom pankreatite tyazhelogo techeniya [Markers of endothelial dysfunction and their prognostic value in severe acute pancreatitis]. Fundamentalnye issledovanija [Fundamental research]. 2013;9-3:355-361. (Russian).

8. Klimenko MV. Osobennosti citokinovoj reaktivnosti pri ostrom i hronicheskom pankreatite [Features of cytokine reactivity in acute and chronic pancreatitis]. Ukrainskij zhurnal hirurgii [Ukrainian journal of surgery]. 2013;2(21):111-114. (Russian).
9. Veligotskiy NN, Klimenko MV, Arutyunov SE. Rol transformiruyushego faktora rosta $v$ opredelenii tyazhesti ostrogo pankreatita [Role of transforming growth factor in determining the severity of acute pancreatitis]. Suchasni medychni tehnologii [Modern Medical Technology]. 2012;4(16):53-56. (Russian).

10. Warzecha Z, Dembiński A, Ceranowicz P, Dembiński M, Kownacki P, Konturek SJ, Tomaszewska R, Stachura J, Hładki W, Pawlik WW. Immunohistochemical expression of FGF-2, PDGF-A, VEGF and TGF beta RII in the pancreas in the course of ischemia/reperfusion-induced acute pancreatitis. Journal of Physiology and Pharmacology. 2004;55(4):791-810.

11. Frossard JL, Hadengue A, Pastor CM. New Serum Markers for the Detection of Severe Acute Pancreatitis in Humans. American Journal of Respiratory and Critical Care Medicine. 2001;164(1):162-170. doi: 10.1164/ajrccm.164.1.2008026.

12. Ketlinskij SA, Simbircev AS. Citokiny [Cytokines]. St. Petersburg: Foliant; 2008. 552 p. (Russian).

13. Manohar M, Verma AK, Venkateshaiah SU, Sanders NL, Mishra A. Pathogenic mechanisms of pancreatitis. World Journal of Gastrointestinal Pharmacology and Therapeutics. 2017;8(1):10-25

14. Roxvall LI, Bengtson LA, Heideman JM. Anaphylatoxins and terminal complement complexes in pancreatitis. Evidence of complement activation in plasma and ascites fluid of patients with acute pancreatitis. Archives of Surgery. 1990;125(7):918-921. doi:10.1001/archsurg.1990.01410190116019.

15. Bettac L, Denk S, Seufferlein T, Huber-Lang M. Complement in Pancreatic Disease - Perpetrator or Savior? Frontiers in Immunology. 2017;8:15. doi: 10.3389/fimmu.2017.00015.

16. Parfenov IP, Belousov VA, Yarosh AL, Karpachev AA, Soloshenko AV. Sovremennye predstavlenija o roli citokinov $\checkmark$ patogeneze ostrogo pankreatita [The contemporary view on cytokines role in the pathogenesis of acute pancreatitis]. Nauchnye vedomosti Belgorodskogo gosudarstvennogo universiteta. Serija, Medicina. Farmacija [Belgorod State University Scientific Bulletin. Medicine. Pharmacy]. 2011;16(111):40-45. (Russian). 
17. Ueda $T$, Takeyama $Y$, Yasuda $T$, Matsumura N, Sawa $H$, Nakajima T, Ajiki T, Fujino Y, Suzuki Y, Kuroda Y. Significant elevation of serum interleukin-18 levels in patients with acute pancreatitis. Journal of Gastroenterology. 2006;41(2):158165. doi: 10.1007/s00535-005-1735-4.
18. Nielsen JS, McNagny KM. Novel functions of the CD34 family. Journal of Cell Science. 2008;121(Pt 22):36833692. doi: $10.1242 / \mathrm{jcs} .037507$.

19. de Almeida JLJ, Jukemura J, Coelho AMM, Patzina RA, Machado MCC, da Cunha JEM. Inhibition of cyclooxygenase-2 in experimental severe acute pancreatitis. Clinics. 2006;61(4):301-306.
Конфликт интересов. Авторы заявляют об отсутствии конфрликта интересов.

Финансирование. Исследование проведено без спонсорской поддержки.

Соответствие принципам этики. Исследование одобрено локальным этическим комитетом.

Сведения об авторах:

Белорусец Виктор Николаевич; Брестская областная больница; e-mail: victorbelorusets@yandex.ru; ORCID: 0000-0001-8150-0207

Карпицкий Александр Сергеевич, д-р мед. наук професcop; Брестская областная больница; e-mail: bob@brest.by; ORCID: 0000-0001-8900-8890

Летковская Татьяна Анатольевна, канд. мед. наук, доцент; Белорусский государственный медицинский университет; e-mail: patanat@bsmu.by
Conflict of interest. The authors declare no conflict of interest.

Financing. The study was performed without external funding.

Conformity with the principles of ethics. The study was approved by the local ethics committee.

Information about authors:

Belorusets Victor; Brest regional hospital; e-mail: victorbelorusets@yandex.ru; ORCID: 0000-0001-8150-0207

Karpitski Alexander Sergeevich, PhD, MD (Medicine), Professor; Brest regional hospital; e-mail: bob@brest.by; ORCID: 0000-0001-8900-8890

Letkovskaya Tatyana Anatolyevna, PhD (Medicine), Associate Professor; Belarusian State Medical University; e-mail: patanat@bsmu.by
Поступила: 22.10.2019

Принята к печати: 14.11.2019
Received: 22.10 .2019

Accepted: 14.11.2019

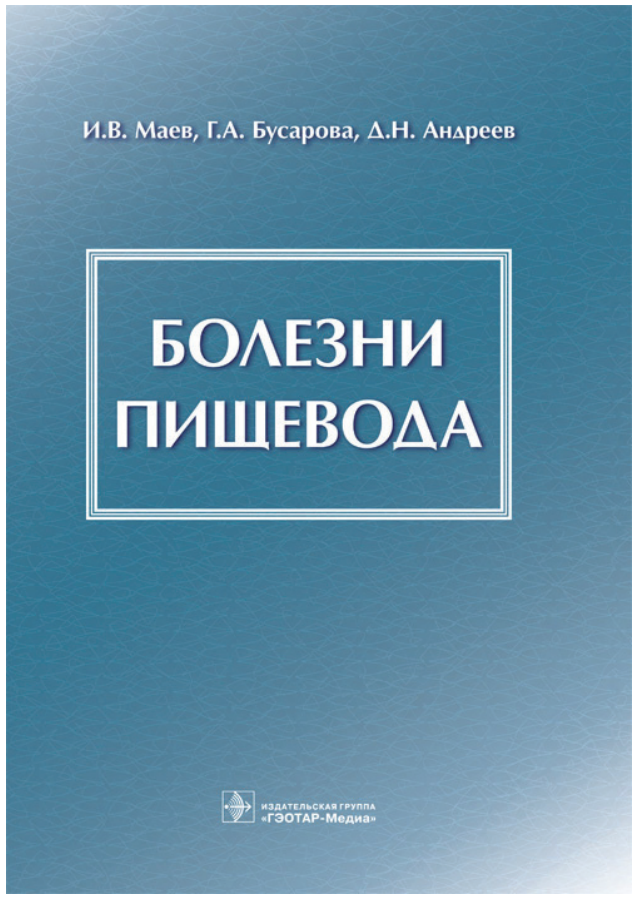

Маев, И. В. Болезни пищевода / И. В. Маев, Г. А Бусарова, Д. Н. Андреев. - Москва : ГЭОТАР-Медиа, 2019. - 648 с. - ISBN 978-5-9704-4874-8.

Издание посвящено вопросам заболеваний пищевода. В книге приведены подробные сведения о строении и фризиологии пищевода, рассмотрены классификация, этиология, патогенез, клиническая картина, современная лабораторная и инструментальная диагностика болезней пищевода, их лечение и профилактика. Книга предназначена гастроэнтерологам, терапевтам, врачам общей практики, хирургам и онкологам.

Авторы, редакторы и издатели приложили максимум усилий, чтобы обеспечить точность приведенных в монографрии данных, однако, с учетом постоянной динамики медицинской науки, эти сведения могут изменяться. 